\title{
Metody analiz numerycznych procesów spawania złożonych konstrukcji
}

\author{
Numerical analyses methods of complex welded structures
}

\begin{abstract}
Streszczenie
W artykule przedstawione zostały metody obliczeniowe stosowane $\mathrm{w}$ analizach numerycznych procesów spawania konstrukcji złożonych z wielu elementów i złączy spawanych. Opisane zostały metody obliczeniowe stosowane w nowoczesnym oprogramowaniu wykorzystującym metodę elementów skończonych i stosowane z powodzeniem od dłuższego czasu w przemysłowych aplikacjach programu SYSWELD. Przedstawiony został również przykład prowadzenia analiz techniką shrinkage jako nowoczesnego podejścia do zagadnień obliczeniowych złożonych konstrukcji spawanych, pozwalającego na sprawną i szybką optymalizację procesu spawania w celu minimalizacji odkształceń konstrukcji.
\end{abstract}

Słowa kluczowe: MES; analizy numeryczne; metoda skurczu; Sysweld; odkształcenia

\begin{abstract}
The article presents calculation methods used in numerical analyses of welded structures made from many elements and joints. Presented simulation methods used in modern FEM software are successfully used from longer time for industrial application of SYSWELD. This article described also an example of shrinkage method calculations as modern approach to the calculation problem of complex welded constructions which allows to smooth and fast optimize the welding process to achieve the distortion minimalization.
\end{abstract}

Keywords: FEM; numerical analyses; shrinkage method; Sysweld; distortions

\section{Wstęp}

Ciągły postęp technologiczny w dziedzinie komputerów powoduje, że dysponujemy coraz większą mocą obliczeniową maszyn, które na co dzień są naszym narzędziem pracy. Oczywiście moc ta jest wykorzystywana w różny sposób - od zastosowań rozrywkowych, przez zwykłą codzienną pracę po zastosowania profesjonalne. Jest to jednak narzędzie, które jeszcze nie tak dawno było niedostępne lub istniało tylko w literaturze z zakresu fantastyki. Dostęp do ogromnych zasobów mocy obliczeniowej pozwala na coraz śmielsze spoglądanie w kierunku zastosowań metod obliczeniowych w bardzo złożonych analizach numerycznych. Jest to konieczne, ponieważ rozwój technologiczny powoduje również, że sięgamy po coraz bardziej zaawansowane materiały konstrukcyjne, których ceny niejednokrotnie skutecznie hamują wykonywanie licznych prób technologicznych oraz testów przedprodukcyjnych. Z drugiej strony śmielej projektujemy duże, skomplikowane konstrukcje, gdzie niejednokrotnie odnalezienie wzajemnego wpływu wielu parametrów procesu wytwórczego jest niemożliwe do uzyskania klasycznymi metodami obliczeniowymi lub na podstawie nawet wieloletniego doświadczenia i wiedzy inżynierskiej [1 $\div 3$.

W takiej sytuacji z pomocą przychodzą zaawansowane programy do analiz numerycznych procesów technologicznych, oparte na metodzie elementów skończonych. Analizy numeryczne procesów spawania to obecnie bardzo nowoczesne, a jednocześnie wydajne narzędzie wspomagające prace inżynierów. Są to jednak również najbardziej złożone zagadnienia wymagające szerokiej i rzetelnej wiedzy zarówno z zakresu metod obliczeniowych, jak i technologii oraz zagadnień materiałowych. Jednym z najbardziej zaawansowanych pakietów do tego typu analiz jest Welding Simulation Solution firmy ESI Group [2,3].

Dr inż. Tomasz Kik - Politechnika Śląska; dr inż. Marek Slováček- MECAS ESI

Autor korespondencyjny/Corresponding author. tomasz.kik@polsl.pl 


\section{Metody obliczeniowe}

W zależności od stopnia złożoności rozwiązywanego zagadnienia, użytkownik ma możliwość prowadzenia analiz numerycznych przy wykorzystaniu następujących metod (rys. 1):

- ciągła analiza procesu spawania (ang. transient method),

- metoda Local-global,

- analiza metodą skurczu (ang. 'shrinkage' method) [1].

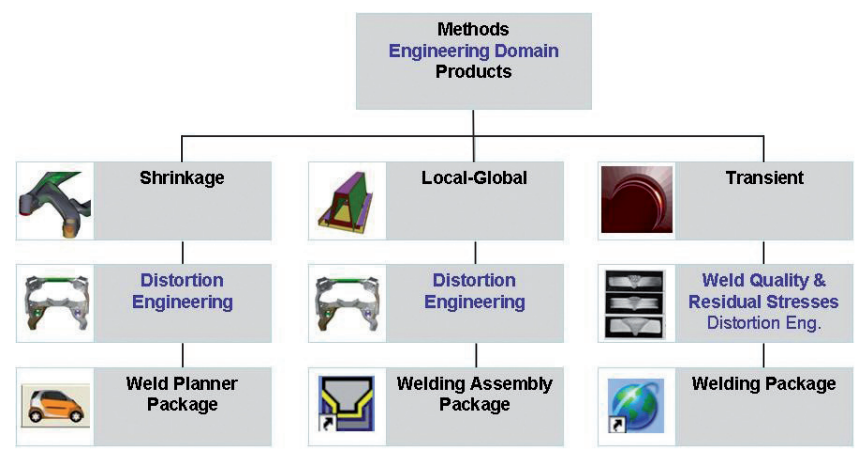

Rys. 1. Metody obliczeniowe i narzędzia w pakiecie Welding Simulation Solution firmy ESI Group [1]

Fig. 1. Calculation methods and tools in ESI Group Welding Simulation Solution package [1]

W każdej z tych metod użytkownik uzyskuje dostęp do możliwości obliczeniowych, dostosowanych do rozwiązywanego zagadnienia i oczekiwanych wyników.

Ciągła analiza procesu spawania (transient analysis - TW) nazywana również metodą 'step by step' oparta jest na obliczeniach związanych z poruszającym się matematycznym modelem źródła ciepła. Obliczenia wykonywane są dla każdej, kolejnej chwili czasowej zwiększanej o zadany krok czasowy, który jest dostosowywany automatycznie lub ustalany przez użytkownika. Analiza ta podzielona jest na dwie części: obliczenia zjawisk termicznych i związanych z nimi zmian metalurgicznych oraz zjawisk mechanicznych (tj. rozkłady naprężeń oraz odkształceń itp.). Przy uwzględnieniu faktu wykonywania obliczeń w każdej kolejnej chwili czasowej, użytkownik po zakończeniu analizy otrzymuje potężny zbiór danych termometalurgicznych i mechanicznych dotyczących symulowanego procesu. Ceną takiego rozwiązania jest wydłużony czas trwania obliczeń. Jest to główny powód, dla którego obliczenia dużych konstrukcji spawanych z wieloma spoinami wykorzystywane są inne techniki obliczeniowe $[1,2,4 \div 7]$.

Jedną z nich jest modyfikacja techniki transient polegająca na zastosowaniu odpowiednio przygotowanego cyklu cieplnego od razu na jednym lub kilku obszarach (elementach) modelu jednocześnie. Technika ta nazywana jest metodą Macro bead deposit (MBD). Rzeczywista trajektoria spawania podzielona jest na podobszary tak, aby zachowane były kolejność i kierunki spawania. Liczba tych podobszarów oraz krok czasowy, definiowane są w oparciu o parametry technologiczne procesu spawania, jak również doświadczenie osoby pracującej z tą metodą. Mimo że technika ta wymaga znacznie większego doświadczenia od osoby przygotowującej model do obliczeń, jej zastosowanie znacznie skraca czas obliczeń. Pozwala to zatem na wykonywanie analiz numerycznych dużych, skomplikowanych konstrukcji przy jednoczesnym zachowaniu wysokiej zgodności wyników tych analiz z rzeczywistością [1 $\div 3]$.

Metoda Local-global to technika szczególnie istotna w przypadku analiz numerycznych bardzo dużych konstrukcji z dużą liczbą złączy spawanych. Stosowana jest w sytuacjach, gdy standardowa technika obliczeń (transient method) a nawet MBD nie jest możliwa do przeprowadzenia. Główną ideą techniki Local-global jest założenie, że proces spawania prowadzi do lokalnych zmian rozkładu naprężeń i odkształceń plastycznych, natomiast efektem tego w skali globalnej jest określony stan odkształceń. Lokalne efekty procesu spawania określane są $\mathrm{w}$ tym przypadku za pomocą modeli obliczeniowych pojedynczych złączy spawanych z wykorzystaniem wcześniej wspomnianych technik. Wyniki lokalnych analiz są następnie przenoszone do modelu globalnego (całej konstrukcji) w celu określenie całkowitych odkształceń konstrukcji. Pewnym ograniczeniem tej metody obliczeniowej jest to, że wynikiem analiz są tylko odkształcenia konstrukcji oraz siły wewnętrzne i momenty w określonych warunkach zamocowania. Poziomy naprężeń oraz rozkłady poszczególnych faz metalurgicznych określone są jedynie w modelach lokalnych $[1 \div 3]$.

Analiza metodą skurczu (Shrinkage method - SM) z wykorzystaniem pakietu WELD PLANNER lub najnowszego rozwiązania pod nazwą VISUAL ASSEMBLY, pozwala na wykonywanie szybkich analiz odkształceń konstrukcji z bardzo dużą liczbą złączy spawanych i zgrzewanych. Dodatkowo w module VISUAL ASSEMBLY możliwe jest obecnie uwzględnienie np. historii z procesu tłoczenia blach, sposobu pozycjonowania i mocowania elementów łączonych, efektu sprężynowania, ustalania baz mocujących, różnych technik łączenia i inne.

Jak już wspomniano wcześniej, technika ta opiera się na wykorzystaniu metod numerycznej analizy skurczu. Jest ona narzędziem, które pozwala w bardzo krótkim czasie na określenie odkształceń złożonej konstrukcji spowodowanych procesem spawania oraz bardzo szybkie i efektywne stworzenie planu spawania, określenie sposobu i sekwencji mocowania elementów oraz optymalizacji kolejności spawania. Dodatkową zaletą tej metody obliczeń jest fakt, że możliwe jest stosowanie elementów typu shell do budowy tzw. model powłokowych (znaczne przyspieszenie obliczeń). Istnieje również możliwość prowadzenia obliczeń na modelach zbudowanych z elementów typu $3 D$ solid oraz modelach łączących elementy typu solid $z$ elementami typu shell $[1 \div 3]$.

\section{Distortion engineering jako rozwiązanie problemów z odkształceniami konstrukcji spawanych}

Wzajemne połączenie zależności sposobu zamocowania elementów konstrukcji do spawania oraz występujących w niej w trakcie i po procesie naprężeń i odkształceń jest znane każdemu spawalnikowi. Jest to odwieczny problem, z którym zmaga się inżynier projektując oprzyrządowanie mocujące. Również konstrukcje składają się obecnie z większej liczby elementów i złączy, wykonywanych w odpowiedniej sekwencji montażowej. W przypadku skomplikowanych i/lub dużych konstrukcji, doświadczalne ustalenie chociażby samej kolejności spawania, prowadzącej do powstania minimalnego poziomu odkształceń, staje się praktycznie niemożliwe. Stopień skomplikowania powoduje również to, że jak już wspomniano, nie jest możliwe wykonanie klasycznych analiz numerycznych technikami TW lub MBD ze względu na nadal jeszcze niedostateczne zasoby pamięci oraz bardzo długi czas prowadzenia takich obliczeń. Jednakże zastosowanie specjalnych technik obliczeniowych pozwala na wykonanie takich analiz. Co prawda wynikami analiz będą jedynie odkształcenia konstrukcji, aczkolwiek właśnie te zagadnienia są zwykle przyczyną głównych problemów w przypadku montażu złożonych konstrukcji 
spawanych. Poszukiwany jest zwykle kompromis pomiędzy sposobem zamocowania (stopniem usztywnienia konstrukcji) a poziomem naprężeń i odkształceń, rysunek 2 . Drugim problemem jest wspomniana już zmiana kolejności spawania, która dodatkowo może być skomplikowaną, złożoną sekwencją zmiennego zamocowania elementów i rosnącego przesztywnienia konstrukcji wraz z postępem montażu.

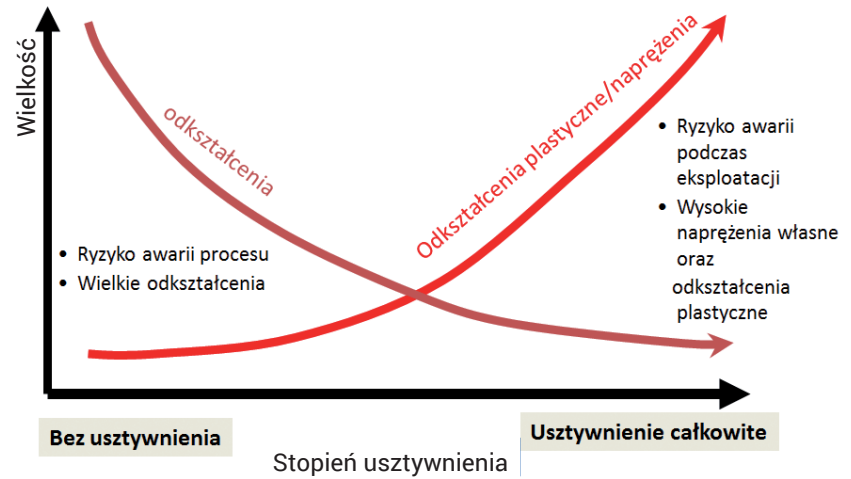

Rys. 2. Przeciwstawne oddziaływanie sztywności konstrukcji na odkształcenia plastyczne oraz naprężenia własne [6]

Fig. 2. Opposing impact of structural stiffness on distortions and residual stresses [6]

W przypadku metody skurczu, obliczenia zjawisk termicznych i związanych z nimi zmian metalurgicznych nie są prowadzone. Wykorzystywane są tylko wyniki analizy zjawisk mechanicznych zachodzących w trakcie procesu spawania. W dużym uproszczeniu można taką sytuację opisać za pomocą następującej zależności:

\section{Skurcz cieplny = współczynnik rozszerzalności cieplnej $x$ zmiana temperatury}

Podsumowując, cykl cieplny powoduje najpierw rozszerzenie się pewnego obszaru materiału w wyniku jego nagrzewania, a następnie skurcz, który jest spowodowany określonymi warunkami stygnięcia i odprowadzania ciepła z tej strefy. Jeżeli w procesie stygnięcia pewne obszary złącza ulegają skurczowi, to zadaniem użytkownika jest znalezienie pewnej reprezentatywnej wartości siły, która ten skurcz powoduje. Jeżeli taka wartość zostanie określona to całość analizy może zostać przeprowadzona zgodnie z założeniami metody i obliczenia zajmą znacznie mniej czasu niż klasyczna analiza typu transient.

W celu znalezienia reprezentatywnej siły powodującej skurcz konieczne jest przeprowadzenie procesu kalibracji. Z tego względu tworzony jest specjalny model lokalny (wybrane złącze z całej kostrukcji), na który przeprowadzana jest klasyczna analiza typu transient i określane są odkształcenia w ściśle określonych miejscach modelu. Następnie taki sam model obliczany jest techniką shrinkage. Otrzymane w wyniku analizy odkształcenia są następnie porównywane do modelu z klasycznej analizy i dane wejściowe są poddawane kalibracji tak, aby uzyskać zbliżone wartości. Po ich kalibracji mogą zostać przeniesione do modelu całej konstrukcji. W przypadku, gdy w konstrukcji znajduje się duża liczba takich samych złączy (rodzaj złącza i wymiary poprzeczne spoiny) proces ten ulega znacznemu przyspieszeniu w czasie $[1,2]$.

Użytkownik definiując własności ściegu, określa jedynie jego trajektorię oraz szerokość. Parametrem za pomocą którego zmienia się wartość siły reprezentatywnej w przypadku tej metody obliczeń jest promień rury/sfery (tube/ sphere) obejmującej węzły siatki modelu w pewnej odległości od założonej trajektorii ściegu (osi spoiny), rysunek 3 . Wszystkie węzły siatki znajdujące się wewnątrz obszaru zamykanego przez jej promień poddane zostaną działaniu skurczu. Zwiększając wartość tego promienia możliwe jest takie ustalenie warunków oddziaływania skurczu, aby wyniki modelu lokalnego tej techniki zbliżyły się do wyników uzyskanych w analizie lokalnej typu transient [1,2].
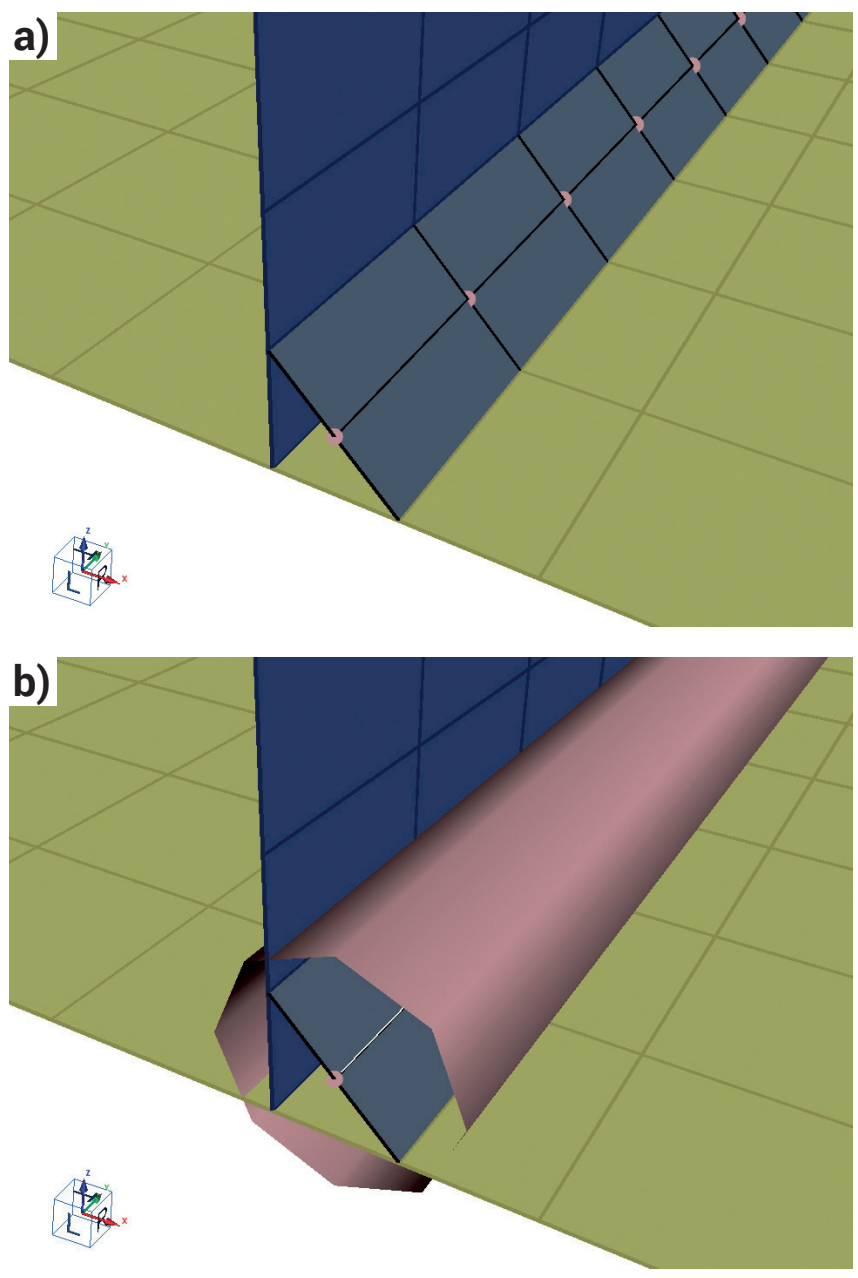

Rys. 3. Widok fragmentu modelu złącza teowego wykonany z elementów typu shell a) z zaznaczoną trajektorią (osią spoiny), b) z obszarem oddziaływania skurczu (tube) [1]

Fig. 3. View of part of shell T-joint model a) with visible trajectory (weld axis), b) with area of shrinkage influence (tube) [1]

\section{Przykład obliczeniowy}

W celu zaprezentowania opisywanej techniki obliczeń przygotowano przykład, który ze względu na rozmiary modelu oraz ilość ściegów, byłby bardzo czasochłonny, a w przypadku niedostatecznej mocy obliczeniowej komputera nawet niemożliwy do obliczenia klasyczną techniką typu transient. Przykładowa konstrukcja składała się z elementów płyty dolnej oraz profili spawanych do płyty za pomocą 86 spoin wykonywanych wg zadanej kolejności, rysunek 4. Model dyskretny składał się z 94807 elementów typu shell oraz 94398 węzłów. Konstrukcja do spawania zamocowana była w 6 miejscach płyty dolnej (rys. 4). Górne elementy były sczepiane przed spawaniem. Po spawaniu całość została uwolniona z oprzyrządowania mocującego. Dla uproszczenia analizowanego przykładu, przyjęto założenie, że wszystkie spoiny są takich samych rozmiarów, stąd kalibracja została wykonana tylko dla jednego rodzaju złącza. 

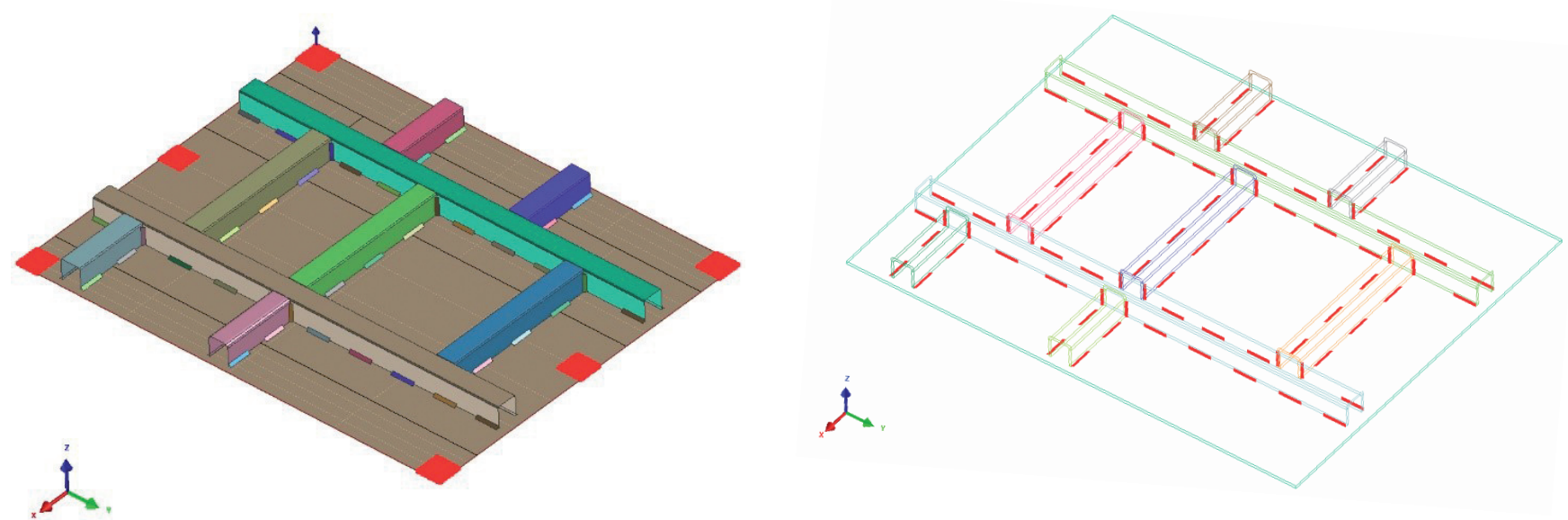

Rys. 4. Widok modelu konstrukcji spawanej (po lewej) z zaznaczonymi spoinami (po prawej)

Fig. 4. View of welded construction model (on the left) with visible joints (on the right)

Kalibracja modelu obliczeniowego w technice shrinkage, jak już wcześniej wspomniano, wymaga porównania odkształceń w charakterystycznych punktach modelu i takiego dostosowania obszaru obejmowanego skurczem (za pomocą zmiany promienia narzędzia tube), aby wartości te były zbliżone. W tym celu zbudowano trójwymiarowy model składający się z 73480 elementów typu 3D solid oraz odpowiadający mu model składający się z 7891 elementów typu shell ze spoinami pachwinowymi po obu stronach profilu, rysunek 5 . Następnie przeprowadzono obliczenia obu modelu wraz z kalibracją modelu w technice shrinkage.

Po uzyskaniu zbliżonych wartości odkształceń, dane wejściowe przeniesiono do modelu całej analizowanej konstrukcji i przeprowadzono obliczenia przy założeniu określonej kolejności wykonywania ściegów, rysunki 6 i 8. Kompletna analiza odkształceń w przypadku opisywanego modelu do kalibracji trwała ok. 2 minut co w porównaniu do czasu obliczeń ok. 2 godzin potrzebnego na pełną analizę termo-metalurgiczną i mechaniczną w przypadku obliczeń wykonanych techniką transient, stanowi o korzyściach stosowania tej metody w przypadku bardziej skomplikowanych zagadnień. Dodatkowo należy wspomnieć, że użytkownik w tym przypadku dysponuje bardzo wygodnym narzędziem pod nazwą Sequence Manager, gdzie w sposób tabelaryczny rozmieszczone są poszczególne operacje spawania i mocowania elementów. Pozwala to na szybkie i bardzo wygodne zmiany np. kolejności wykonywania spoin czy mocowania elementów w celu prowadzenia optymalizacji sekwencji procesu spawania, rysunek 7. Należy jednak pamiętać, że w przypadku metody shrinkage wynikiem obliczeń są jedynie odkształcenia spawanego elementu. Z kolei sporą zaletą tego rozwiązania jest również fakt, że baza materiałowa użyta w obliczeniach jest znacznie mniej skomplikowana (nie jest wymagane opisywanie przemian metalurgicznych).

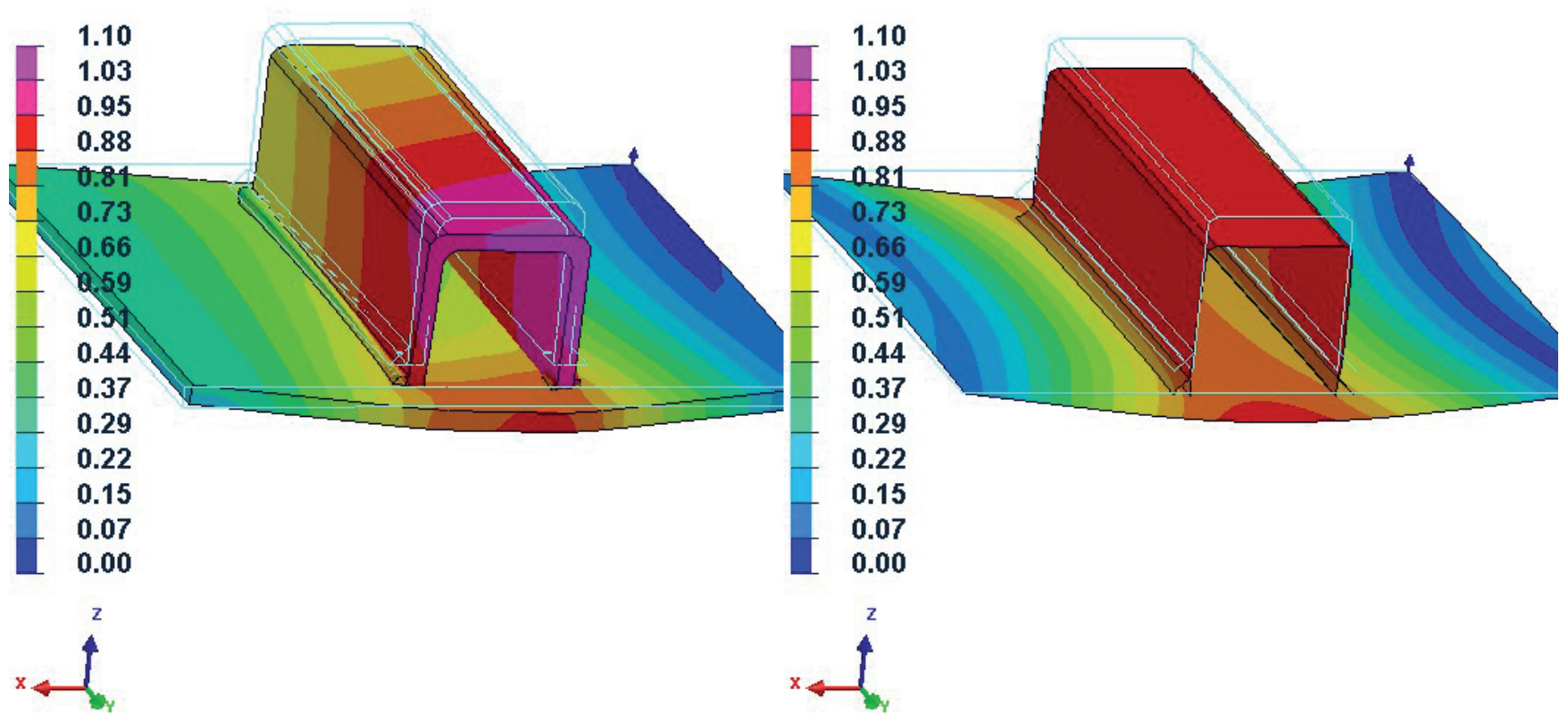

Rys. 5. Porównanie wartości i rozkładu odkształceń - widok modelu do analizy typu transient (po lewej) oraz odpowiadającego mu modelu do analizy typu shrinkage (po prawej)

Fig. 5. Distortion values and distribution comparison - view of transient analysis model (on the left) and corresponding shrinkage model (on the right) 


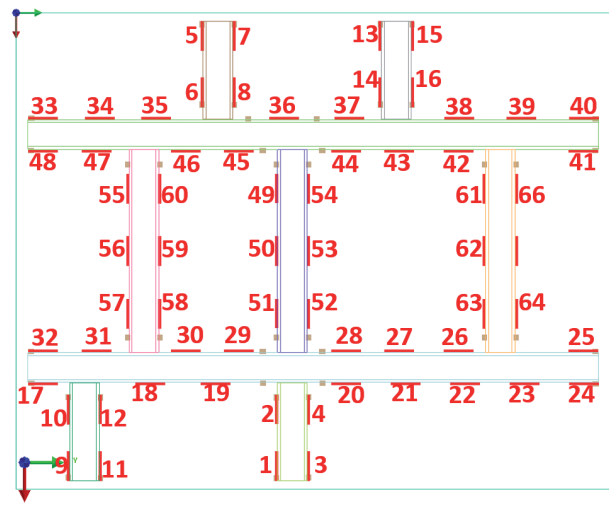

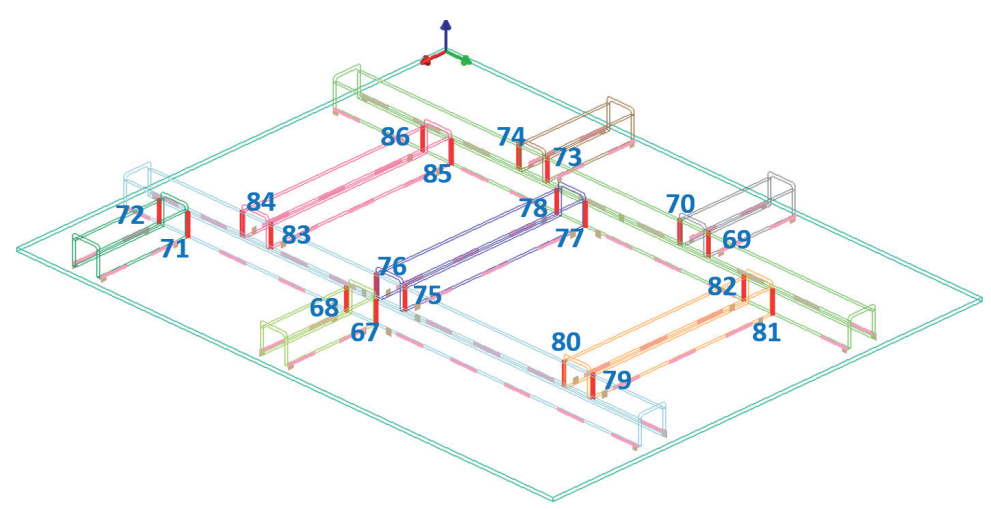

Rys. 6. Rozmieszczenie spoin i kolejność ich wykonywania na analizowanej konstrukcji Fig. 6. Welds arrangement and welding sequence on analysed structure

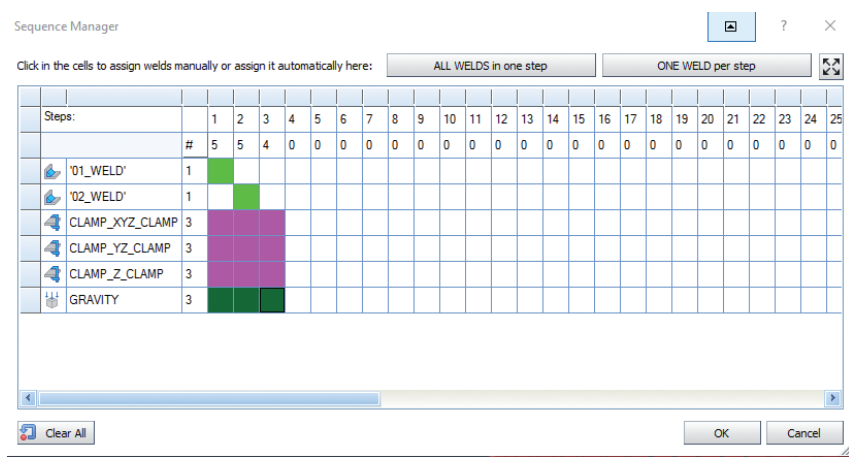

Rys. 7. Okno menadżera kolejności wykonywania operacji spawania w module Visual Assembly

Fig. 7. Sequence manager window in Visual Assembly module

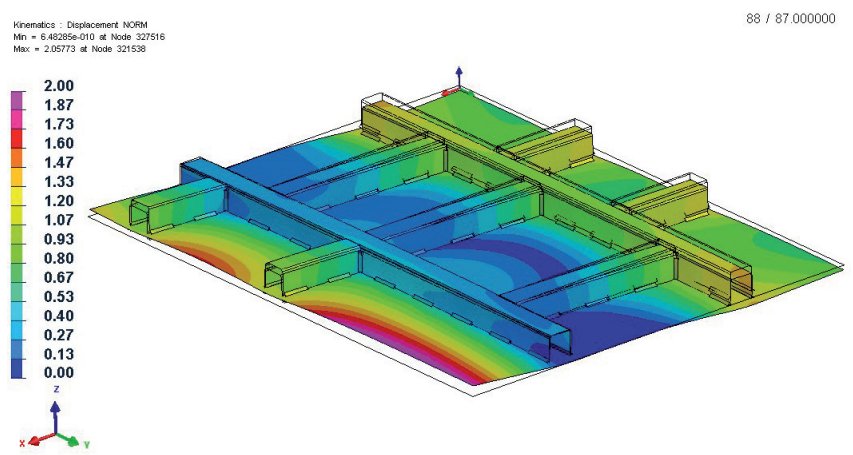

Rys. 8. Rozkład odkształceń modelu analizowanej konstrukcji

Fig. 8. View of analysed construction model distortions distribution

\section{Podsumowanie}

Obecnie głównym wyzwaniem dla przemysłu jest skrócenie czasu potrzebnego na prace projektowe oraz działania badawczo-rozwojowe. Wszystko to ma na celu zwiększenie wydajności oraz skrócenie czasu oczekiwania na produkt końcowy. Określając dopuszczalne tolerancje wykonania detali lub całych konstrukcji z jednej strony musimy brać pod uwagę wymagania dotyczące produktu, a z drugiej nasze możliwości produkcyjne. Natomiast biorąc pod uwagę rozszerzalność cieplną, a następnie skurcz stygnącego metalu w przypadku każdej konstrukcji spawanej, musimy oczekiwać mniejszych lub większych odkształceń. Ich wielkość i rozkład może być optymalizowany poprzez zmianę sposobu zamocowania czy kolejności wykonywania poszczególnych złączy. Czasami odkształcenia nie mogą być zredukowane za pomocą tych czynności i koniecznym staje się ich kompensowanie poprzez czynności wykonywane przed procesem np. odpowiednie ustawienie elementów czy wstępne ich odkształcenie, w celu otrzymania końcowo wymaganych tolerancji wymiarowych. Jednak istotnym jest również fakt, że im większy stopień skomplikowania konstrukcji (większa liczba elementów i spoin), tym trudniej jest takie analizy prowadzić bez użycia nowoczesnego oprogramowania wspomagającego. Stąd istnieje konieczność rozwoju tej dziedziny wiedzy o nowe techniki obliczeniowe oraz budowania świadomości inżynierów, że takie rozwiązania istnieją.

Głównymi zaletami takich rozwiązań są możliwości:

- wykrywania problemów z pozycjonowaniem lub jego niewłaściwym zaprojektowaniem i użyciem;

- analizy efektów: mocowania, spawania oraz np. zastosowania odstępu między spawanymi elementami;

- określenia poprawnego określenia lokalizacji elementów ustalających przy montażu;

- możliwość określenia niebezpieczeństwa powstawania wad/niezgodności w trakcie montażu;

- poprawa wydajności produkcyjnej przez skrócenie czasu na próby technologicznie i znaczne obniżenie kosztów tego etapu.

\section{Literatura}

[1] Welding simulation user guide, Sysweld manual ESI Group, 2016.

[2] M. Slováček, T. Kik: Wykorzystanie analiz numerycznych procesów spawania jako wsparcia technicznego w przemyśle. Cz. 1, Wstęp do zagadnienia symulacji numerycznych procesów spawania, Biuletyn Instytutu Spawalnictwa 2015, R. 59 nr 4, s. 42-47

[3] M. Slováček, M. Vaněk, T. Kik: Wykorzystanie analiz numerycznych procesów spawania jako wsparcia technicznego w przemyśle. Część 2 - metodologia i walidacja, Biuletyn Instytutu Spawalnictwa, 2015, R. 59 nr 5, s. 38-43

[4] T. Padma Kumari, S. Venkata Sairam: Finite Element Analysis of EBW WeIded Joint Using SYSWELD, International Journal of Emerging Technology and Advanced Engineering, vol. 3, Issue 2, February 2013.
[5] F. Kong, J. Ma, R. Kovacevic: Numerical and experimental study of thermally induced residualstress in the hybrid laser-GMA welding process, Journal of Materials Processing Technology 211, (2011), pp. 1102-1111.

[6] T. Kik, M. Slováček, J. Moravec, M. Vaněk: Numerical Analysis of Residual Stresses and Distortions in Aluminium Alloy Welded Joints, Applied Mechanics and Materials, Vols. 809-810, pp. 443-448 DOI: 10.4028/www.scientific.net/AMM.809-810.443

[7] J. Devaux, J. B. Leblond, J. M. Bergheau: Numerical study of the plastic behaviour of a low alloy steel during phase transformation, Proc. Of 1 st Int. Conf. On Thermal Process Modelling and Computer Simulation, J. of Shanghai Jiaotong University, Vol. E-5, N¹, 2000, pp. 206-212. 